\author{
PROCEEDINGS OF THE NUTRITION SOCIETY \\ $A$ report presented at the Annual General Meeting of the Nutrition Society held at the \\ University of York on 5 July 1990
}

\title{
Does the Nutrition Society serve the needs of its overseas members?
}

\author{
BY A. A. JACKSON \\ Chairman of Task Force on Olerseas Members* of The Nutrition Society, 10 Cambridge Court, \\ 210 Shepherds Bush Road, London W6 $7 N J$ \\ INTRODUCTION
}

Nutritionists in the UK have a long history of associations throughout the developed and the developing world. For many individuals career development has included a period of time spent working overseas whereas for others, the preferred career option has been abroad. The UK is rightly proud of the quality of training which has been offered to students of nutrition from overseas. On many occasions the professional and personal friendships developed during this training period represent an important point of contact with the wider body of professional nutritionists. Given these longstanding links it is hardly surprising that many members of the Nutrition Society are resident overseas. In the review of the membership carried out in 1985 the findings showed that as many as one-third of the membership were living overseas (Ashwell \& Cole, 1986).

The Nutrition Society exists to serve the needs of all its members. From time-to-time concern has been expressed in Council that the Society has not been doing as much as it might for its overseas members. These concerns relate especially to those members in developing countries who work in relative isolation. either scientifically or professionally. The question was raised as to whether the Society should or could be doing more for these memburs.

Council set up an ad hoc Committee to:

(1) establish whether overseas members were satisfied by the scrvice they received from the Society and,

(2) identify ways in which the Socicty might address any perceived problems or difficulties expressed by overseas members.

\section{THE QUESTIONNAIRE}

In 1989 a questionnaire was sent out to all overseas members. The questionnaire sought to ascertain the extent to which members were satisfied with the Society and whether their needs were being met in certain areas. This report summarizes the results from that questionnaire.

The questionnaire was sent to 477 members; 242 replies were received from individuals in fifty-three countries. Replies were received from North America $(67,50 \%$

\footnotetext{
* Task Force on Overseas Members: A. A. Jackson (Chairman), J. Henry, S. Ismail, J. P. Landman, B. M. Margetts, R. Neale.
} 


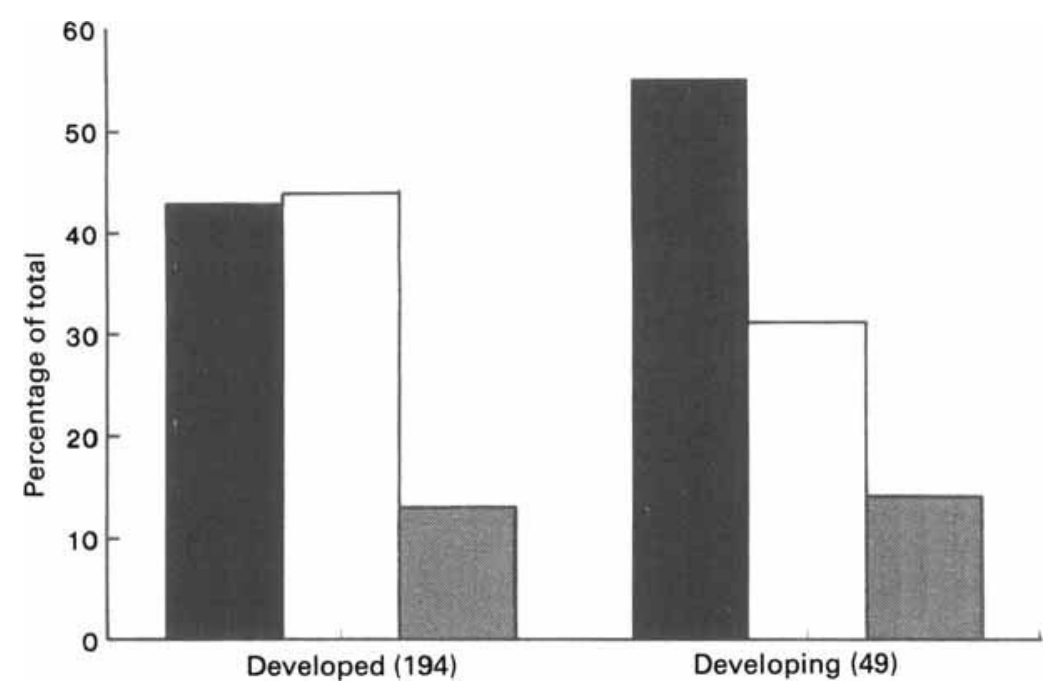

Fig. 1. Per cent distribution of occupational interest by country group.

Human nutritionist

Animal nutritionist

Basic scientists

of those sent), Europe $(67,42 \%)$, Scandinavia $(16,73 \%)$, Asia $(15,34 \%)$, Africa (11, $25 \%)$, Central and South America $(8,57 \%)$, Middle East $(8,33 \%)$, Pacific $(3,100 \%)$ and Caribbean $(3,38 \%)$.

Members were asked about their main occupational interests which fell into three broad categories, animal nutrition, human nutrition, and a small group of basic scientists in physiology or biochemistry. In North America, Europe, Australia and Asia most people were involved in animal nutrition, whereas in Africa. Central and South America, the Pacific, Caribbean and the Middle East the largest group of respondents were human nutritionists. The country groups were subdivided into either developed or developing, for analysis. Fig. 1 shows the percentage with each occupation interest by country group. Of respondents in developing and developed countries 55 and $43 \%$ respectively described their occupation as human nutrition. For those described as animal nutritionists, the percentages were 31 in developing countries and 44 in developed countries. All subsequent presentations are for animal and human nutritionists alone, with the small group of basic scientists being excluded.

Members were asked: 'At present, do you think that the Society meets your needs?' Responses to this question, broken down by occupation and country groups, are summarized in Fig. 2. The most striking observation was that human nutritionists from developing countries were much more likely than any other group, occupation, or country, to think that the Society did not meet their needs $(19 \%$ of human nutritionists from developed countries compared with $50 \%$ from developing countries). In developing countries, newer members were also more likely to feel that the Society did not meet 


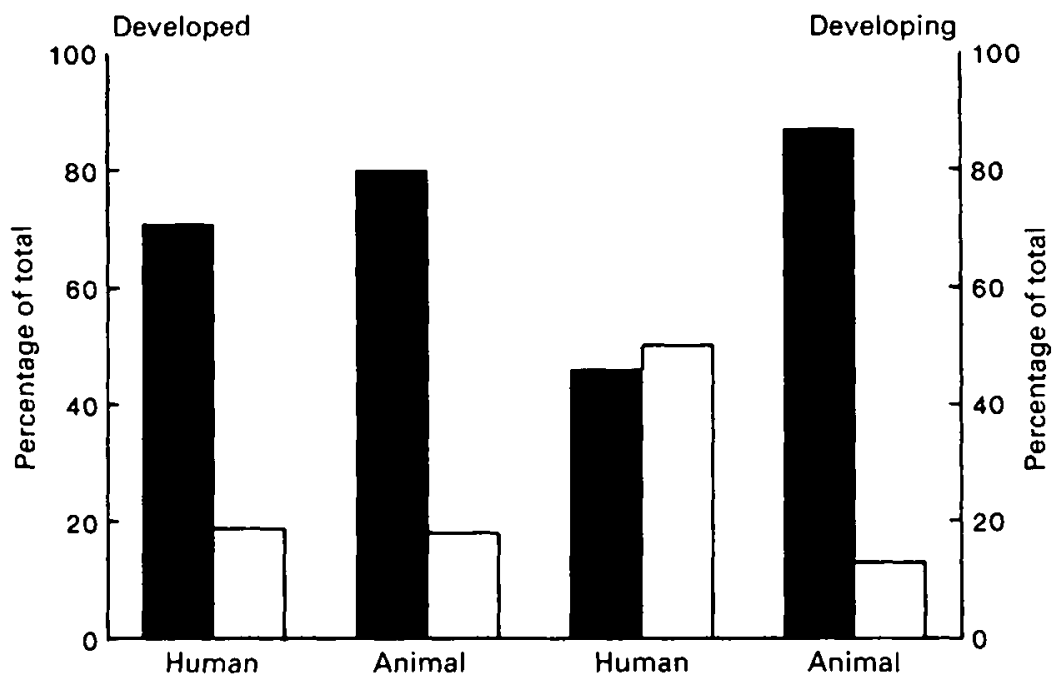

Fig. 2. Per cent distribution of responses to the question 'At present, do you think that the Society meets your needs?', by occupation and country group.

Yes $\square$ No $\square$

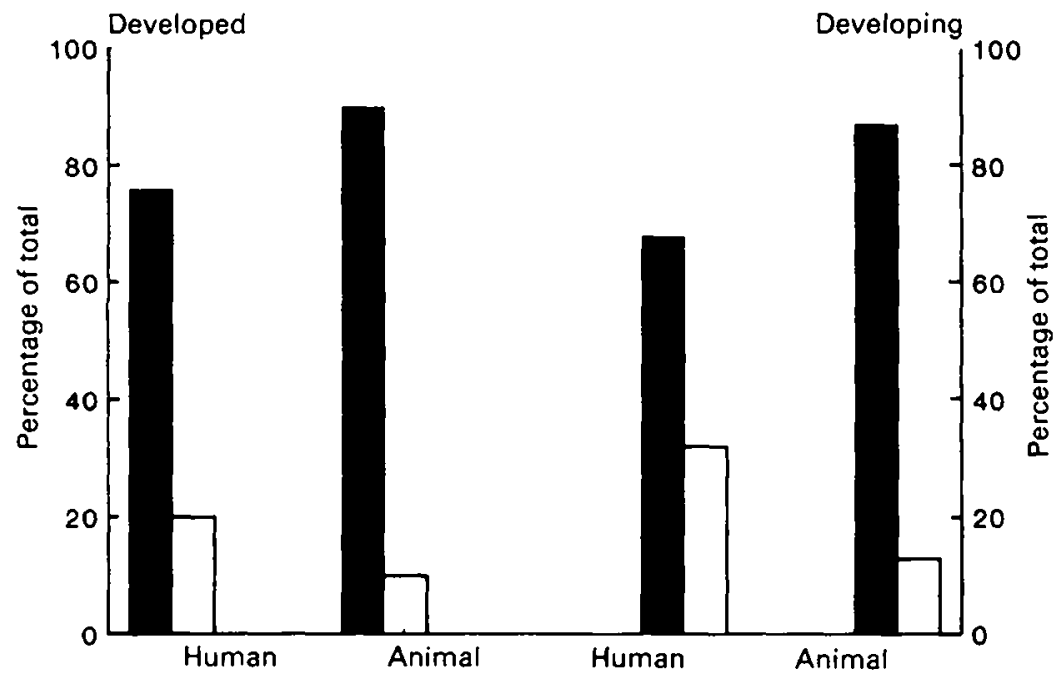

Fig. 3. Per cent distribution of responses to the question 'Is the scope of The British Journal of Nutrition appropriate?', by occupation and country group.

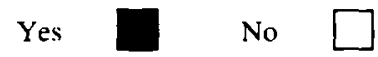

their needs, than members of longer standing ( $52 \%$ of members of less than 5 years standing said no, compared with $20 \%$ of members of more than 11 years standing); in developed countries there was no variation across duration of membership.

Members were asked: 'Is the scope of The British Journal of Nutrition appropriate?'. Results are summarized in Fig. 3. The majority of respondents indicated that they 


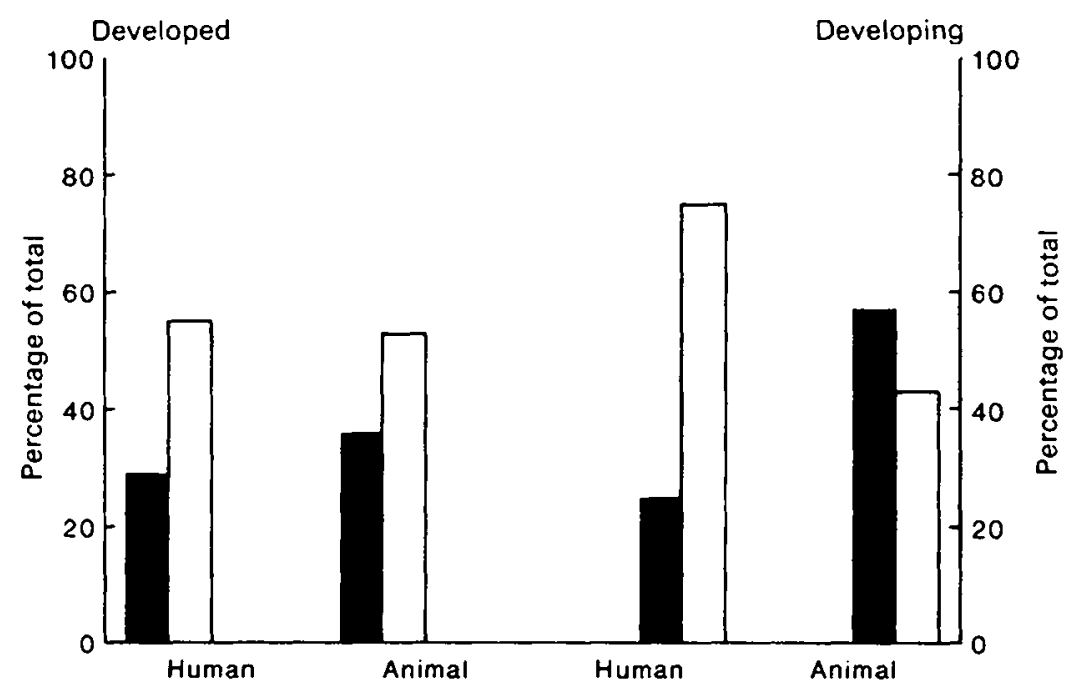

Fig. 4. Per.cent distribution of responses to the question 'Do you feel that the meetings of the Nutrition Society reflect the problems of the less-developed world?', by occupation and country group.

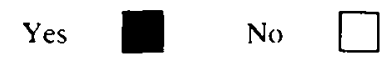

thought the scope of the journal was appropriate. Human nutritionists in general were less likely than animal nutritionists to feel that the journal was appropriate. Human nutritionists in developing countries $(32 \%)$ were less likely than human nutritionists in developed countries $(20 \%)$ to feel that the journal was appropriate.

Members were asked: 'Do you fecl that the meetings of the Nutrition Society reflect the problems of the less-developed world?' (Fig. 4). There was a subset of respondents from developed countries who did not have an opinion on the question, and hence percentages here do not add to 100 . The majority of respondents (53-75\%), except for animal nutritionists in developing countries (43\%), felt that the meetings of the Society did not reflect the problems of the less-developed world. Human nutritionists in developing countries were the most likely to disagree with the proposition $(75 \%)$.

Only $25 \%$ of human nutritionists from developing countries felt that 'Within the Nutrition Society there are sufficient opportunities for stimulation/exchange of ideas and experience'. Of human nutritionists from developed countries $30 \%$ felt that there were insufficient opportunitics for exchange (Fig. 5). Animal nutritionists in developing countries were more likely to think that there was sufficient opportunity for exchanging ideas.

Members were asked whether they would like to see the Society more actively involved in: (a) providing aid/grants to enable short visits to the UK; (b) developing short courses for continuing education; (c) the provision of financial assistance for the organization of meetings locally; (d) facilitating the presentation of papers to meetings of the Nutritior. Society and (e) helping to organize groups locally. Over-all most respondents would like to see the Society more involved in each of the previcusly mentioned areas. On average between 60 and $95 \%$ of nutritionists from developing countries were in favour of wider involvement of the Society in these activitics. In 


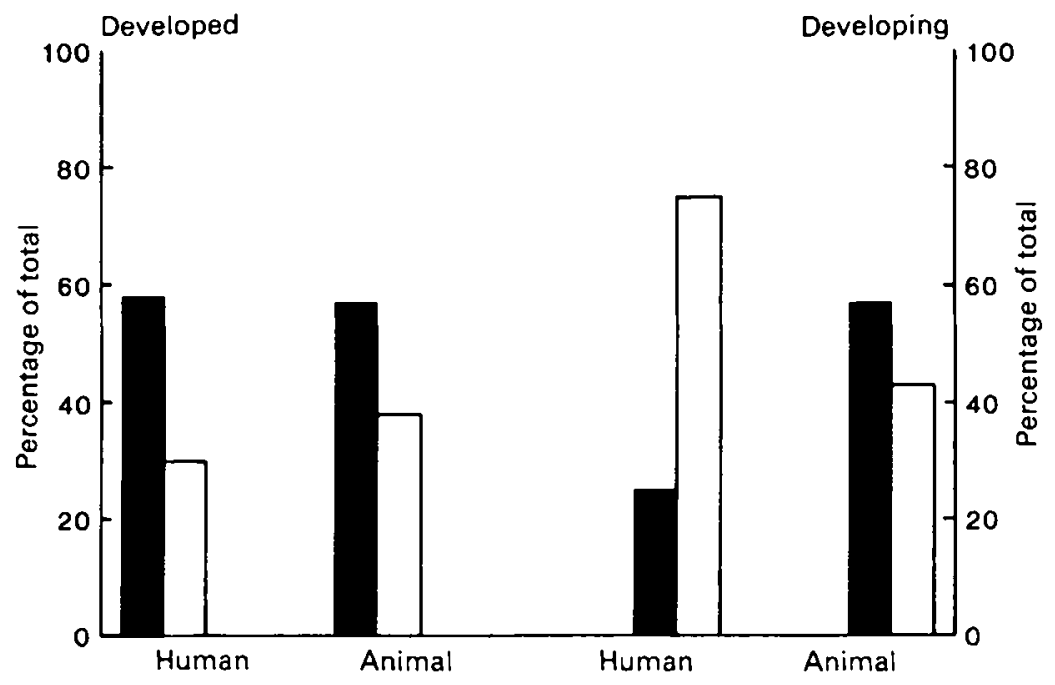

Fig. 5. Per cent distribution of responses to the question 'Within the Nutrition Society, are there sufficient opportunities for stimulation/exchange of ideas and experience?', by occupation and country group.

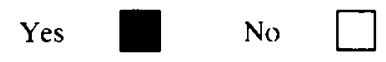

contrast only $45-70 \%$ of nutritionists from developed countries were likely to agree with the wider involvement. The greatest contrast in responses existed for the proposition that the Society be more involved in helping financially to organize meetings locally. Of human nutritionists in developing countries $96 \%$ compared with $54 \%$ of human nutritionists in developed countries, agreed with this proposition (Fig. 6). The comparison for animal nutritionists was 58 and $43 \%$ for respondents from developing and developed countries respectively.

Members were asked: 'Does a lack of funds limit your access to Nutrition Socicty meetings?' (Fig. 7). Most respondents were limited by funds, although the problem was perceived to be considerably worse for those from developing countries.

At the end of the questionnaire members were invited to offer additional comments; twelve wanted to see the Society more actively involved in organizing meetings, or meetings concerned more with issues of obvious relevance to developing countries: eleven wanted greater contacts established between the Society and local organizations: eleven thought the Society served them very well; and eight wanted meetings to be organized on special topics. Of the choice of times offered for the annual meeting of the Society, July, or the summer, was favoured over the spring or autumn.

\section{DISCUSSION}

About half of the members who were sent the questionnaire replied and it is possible that the views expressed by those who responded do not reflect the overall views of the membership overseas. The picture emerged of those engaged in animal nutrition as being older and more satisfied with the Society. This group appears to operate within a well-founded scientific base and is engaged in productive activities of obvious economic 


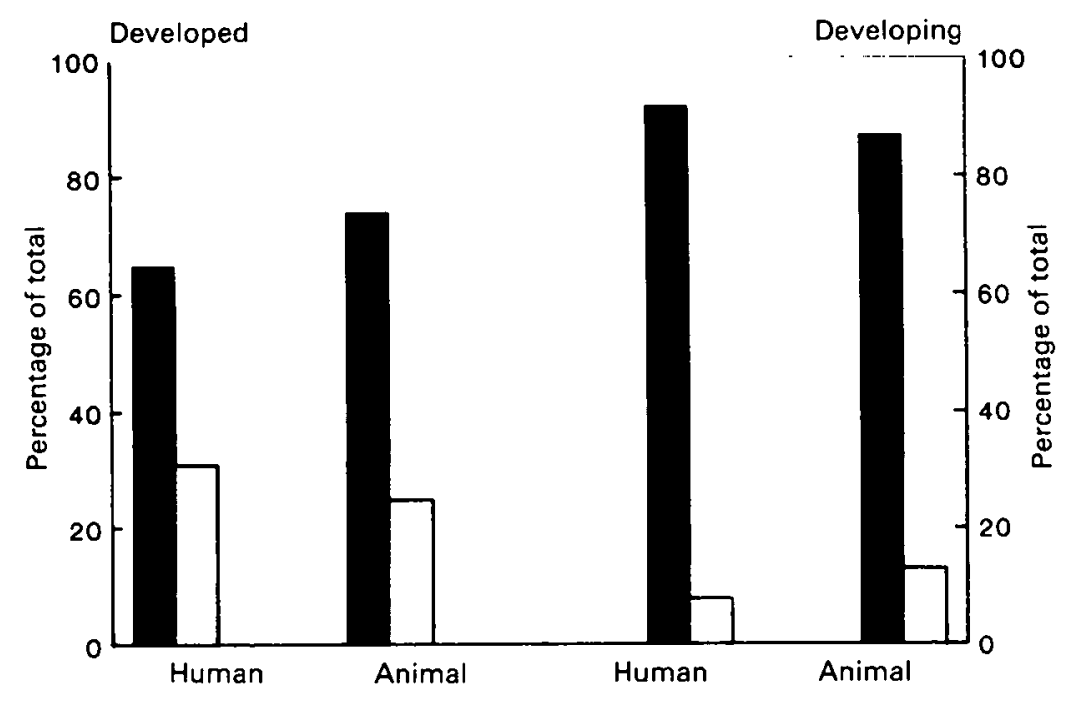

Fig. 6. Per cent distribution of responses to the question 'In each of the following areas indicate whether you would like to see the Society more actively involved, or helping financially to organize semesters/conferences on nutrition in your own area/region/country', by occupation and country group.
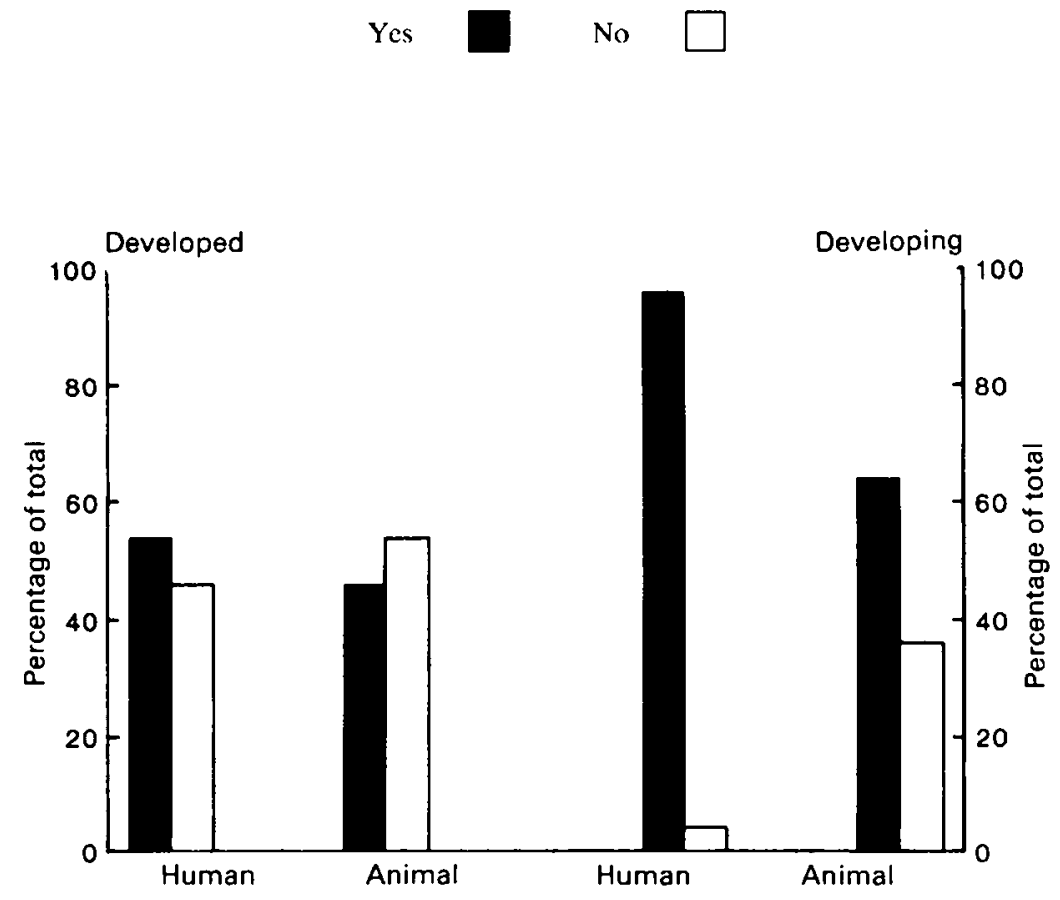

Fig. 7. Per cent distribution of responses to the question 'Does a lack of funds limit your access to Nutrition Society meetings?', by occupation and country group.

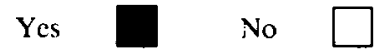


relevance. Human nutritionists, on the other hand, are younger as a group and appear to be more demanding of the facilities or resources which they would like to have available to them. They are engaged in activities which may be seen as being of more welfare or social benefit. Their professional activities may not be directly related to productive activities nor have an economic relevance which is immediately obvious.

There was also a distinction between human nutritionists in developing and developed countries. Human nutritionists in the developing countries are more likely to feel professionally isolated and, therefore, in need of greater support from the Society. They would like the Society to help them keep in touch with what is happening in the wider community of nutritionists. Respondents from developed countries are much more likely to have access to local organizations which can provide appropriate professional support.

\section{CONCLUSIONS}

Several conclusions may be drawn from the survey:

(1) A vehicle is required for improving communications between local and overseas members of the Society. This need is of particular importance for members in developing countries who work in the area of human nutrition.

(2) Overseas members would like to see the Society actively involved in supporting visits to the UK, short courses and presentation of papers at Society meetings.

(3) Help is required in developing countries for organizing local groups and for improving working relations between these groups and the Society.

(4) Access to foreign exchange may be a problem. It would be of assistance if subscriptions to the Society could be made in local currency. This might enable more individuals to join the Society especially in many countries where foreign exchange is difficult.

(5) The British Journal of Nutrition should continue to encourage more papers on topics of interest to human nutritionists in developing countries.

(6) As the meetings of the Society do not reflect the problems of developing countries, efforts should be made to change this situation within the new group structure.

\section{REFERENCE}

Ashwell, M. \& Cole, T. J. (1986). The Nutrition Society in the 1980s: the questionnaire analysis. Proceedings of the Nutrition Society 45, 231-252. 